\title{
Mixed-effects modeling for analyzing land use change in the Brazilian Pantanal subregion of Cáceres
}

\author{
Edinéia A.S. Galvanin ${ }^{\mathrm{a}, *}$, Raquel Menezes ${ }^{\mathrm{b}}$, Murilo H.X. Pereira ${ }^{\mathrm{c}}$, Sandra M.A.S. Neves ${ }^{\mathrm{d}}$ \\ ${ }^{a}$ Department of Mathematics, University of Mato Grosso State, Barra do Bugres 78390-000, Mato Grosso, Brazil \\ ${ }^{\mathrm{b}}$ Department of Mathematics and Applications, Centre of Molecular and Environmental Biology, Minho University, Azurém, 4800-058 Guimarães, Portugal \\ ${ }^{\mathrm{c}}$ Department of Computer Science, University of Mato Grosso State, Barra do Bugres 78390-000, Mato Grosso, Brazil \\ ${ }^{\mathrm{d}}$ Department of Geography, University of Mato Grosso State, Cáceres 78390-000, Mato Grosso, Brazil
}

\section{A R T I C L E I N F O}

\section{Keywords:}

Wetland

Statistical models

Remote sensing

Vegetation cover

Anthropogenic processes

\begin{abstract}
A B S T R A C T
In this paper, we discuss the use of mixed-effects modeling for analyzing land use change in the Brazilian Pantanal subregion of Cáceres, Mato Grosso State, Brazil. The proposed method, easily extendable to similar case studies, consisted of two steps. First, spatio-temporal data, consisting of Landsat images of the study area from 1993, 1999, 2004, 2009, and 2015, were obtained. The data are polygons with numerical data (year and area) and categorical data (land use and soil type). Second, we analyzed the data using four linear mixed models able to incorporate both the fixed and the random effects underlying the clustered data. The proposed models allowed analyzed complex data structures, such as multilevel data, taking into account particularities of each land use type as a function of the year. The models were fitted to identify land use changes over time. In particular, the point estimate of the random slope in the case of the Pasture class, the value of the random slope is 0.043, which indicates an increase of about $21.5 \%$ in hectare over the next 5 years; The point estimate of the slope for the Forest was -0.04 , which indicates a decrease of about $20.5 \%$ in hectare in next 5 years.
\end{abstract}

\section{Introduction}

Understanding the spatio-temporal relationships between natural and anthropogenic changes in ecosystems, including wetlands, is necessary for planning, management, and monitoring of natural resources. Studies of land use and occupation require the adequate characterization of different types of natural vegetation (Rosa, 2003).

The Pantanal is a large wetland containing several types of vegetation (landscape units) forming complex habitats having multiple functions and is an important natural resource. Both flooding and the interactions between these habitats are necessary for their existence (Silva and Girard, 2004; Wantzen et al., 2008). The double seasonality and variations in the flood regime impact structure and floral composition of the wetland, making the habitat more sensitive to anthropogenic processes (Bove et al., 2004; Adamoli, 2005).

Land cover information is essential for proper planning, management, and monitoring of natural resources (Zhu, 1997). In particular, remote sensing data are useful for analyzing changes in terrestrial ecosystems, including dynamic changes in energy and water, plant cover, species composition, and the physical properties of soil. Viable information on the nature of land coverage on the regional and global scale are obtained using synoptic-vision and remote-sensing to map wetland (Csaplovics, 1998; Foody, 2002).

Methods based on land use change (LUC) have been proposed. For example, Weng (2002) investigated LUC dynamics by combining remote sensing data, geographic information systems (GIS), and stochastic modeling. Clements et al. (2014) studied detecting vegetation changes in East Africa using Normalized Difference Vegetation Index (NDVI) data and multiple testing methodologies. Rawat and Kumar (2015) carried out a study on land use/cover change using geospatial techniques. Pramudya et al. (2016) investigated the impact of climate change on agriculture by identifying land use conversions in Landsat satellite images obtained over the course of the last 20 years and conducting logistic regressions.

However, detecting the temporal and spatial details of LUC can be challenging. Studies that consider both statistical and computational methods are promising for analyzing remotely sensed data (Clements et al., 2014). Methodologies that detect LUC must be sensitive and accurate to form environmental policy decisions. Veldkamp and Lambin (2001) argued that statistical analysis is a powerful tool for analyzing LUC because it can test theoretical assumptions, rank relative factors, and rigorously test hypotheses.

\footnotetext{
* Corresponding author.

E-mail address: galvaninbbg@unemat.br (E.A.S. Galvanin).
} 
In this manuscript, a method for analyzing LUC based on a mixedeffects modeling approach is proposed. The model incorporates both fixed and random effects. The former allows one to consider observed explanatory factors and the latter accommodates possible unobserved factors; together, these factors are important for correctly modeling the variable of interest, the area per land use type. This article is organized into four main sections. In Section 2, we describe the study area, the data pre-processing, model specifications, and primary statistical analysis methods. In Section 3, we present the results and discussion. Conclusion remarks are provided in Section 4.

\section{Methods}

\subsection{Study area}

Pantanal biome occupies $1.76 \%$ of Brazil's land area, totaling $150,355 \mathrm{~km}^{2}$ (IBGE, 2004; Brasil, 2009). It is located in the Alto Paraguai (BAP) basin, in the central-west region of the country. The Pantanal of Cáceres is one of the subregions of the Mato Grosso Pantanal, occupying approximately $9.01 \%$ of its land area (Silva and Abdon, 1998).

The Pantanal subregion of Cáceres occupies $12,412 \mathrm{~km}^{2}$, of which $12,371 \mathrm{~km}^{2}(99.66 \%)$ is devoted to the municipality of Cáceres. This municipality is located between the Paraguai river and the municipality of Corumbá, Mato Grosso do Sul (south) and borders the Republic of Bolivia and Pantanal of Poconé (west) (Neves et al., 2008) (Fig. 1).

The study area contains a variety of species adapted to the dynamic flood cycle. The Pantanal subregion of Cáceres has both forested and unforested vegetation and features three principle phyto-physiognomic categories: the Wooded Savanna, the Forest Savanna, and the Grass Savanna (Abdon and Silva, 2006).

According to Dallacort et al. (2014), the mean annual temperature varies from $21^{\circ} \mathrm{C}$ to $32{ }^{\circ} \mathrm{C}$ in the study area. However, in the spring, the maximum daily temperatures may exceed $41^{\circ} \mathrm{C}$. The annual average precipitation is $1400 \mathrm{~mm}$, varying from 800 to $1600 \mathrm{~mm}$. The elevation varies from 90 to $150 \mathrm{~m}$, and there are plateaus varying from 200 to $1200 \mathrm{~m}$ above sea level (ANA, 2005; Alho and Silva, 2012).

The types of vegetation in the Pantanal are influenced by its soil, which has formed from loose sediment dating from Quaternary period. The soil primarily consists of sand, with some areas of clay and soil with a high organic matter content (Pott et al., 2011). The primary types of soil in the study area are: Plinthosols, Planosols, and Gleysols, the presence of which show the influence of hydromorphic processes (Fernandes et al., 2007).

\subsection{Data pre-processing}

In this paper, we propose a method for analyzing LUC in the Pantanal subregion of Cáceres using a mixed-effects modeling approach. The Methodology flowchart is presented in Fig. 2.

Spatio-temporal data for the study were obtained using image composites from the Thematic Mapper (TM) sensor onboard the Landsat 5 (bands 3, 4, and 5) and the Operational Land Imager (OLI) sensor onboard the Landsat 8 (bands 4,5 , and 6 ), both freely available from the image catalogs of the United States Geological Survey (USGS, 2017).

The study area was covered by the following Landsat scenes (paths/ rows): $227 / 71,227 / 72,228 / 71$, and 228/72 (30-m spatial resolution; 185-km swath width; 16-day temporal resolution; and 8-bit or 16-bit radiometric resolutions) (USGS, 2017). The images were from 1993, 1999, 2004, 2009, (Landsat-5), and 2015 (Landsat-8).

Images from 1993, 1999, and 2004 were collected in September, and those from 2009 and 2015 were collected in August; both months are in the dry period. Images were chosen based on the vegetation appearing in the image. During this time in the Savanna (Cerrado), vegetation was undergoing a period of leaf shedding, which allowed the vegetation to be identified.

After the radiometric correction by ArcGIS (version 9.2) (Esri, 2007) of the images obtained by Landsat 5 and 8, the georeferenced images were imported into the Georeferenced Information Processing System (SPRING), version 5.1.8 (Camara et al., 1996). Finally, a mosaic of images of the study area was created.

Next, the Landsat images were processed using an image segmentation algorithm available in the SPRING software, tests with different values of similarity and area were performed.

The best combination for grouping two spectrally similar regions into a single region was the similarity value 10 and area 10 ( $0.9 \mathrm{ha})$ from 1993, 1999 and 2004, similarity 10 and area 16 (1.44 ha) from 2009. In the case of the 2015 image acquired from Landsat 8 , we chose similarity value 10 and area 20 (1.8 hectare).

For classification, six distinct thematic classes of vegetation were considered in this study based on the land use and land cover classes proposed by IBGE (2013): Pasture, formed by grass native to the region and exotic grassland composed of cultivated pastures; Forest, defined by dense or open tree formations with varying degrees of continuity; Savanna, consisting of two classes of vegetation open grasslands and small arboreal vegetation; Water, all water bodies; Burned areas defined by extensions of areas affected by fire; and Other Use, consisting of urban areas, farmhouses and roads.

Finally, the training areas were identified and supervised classification of the images was performed using Bhattacharya's method in SPRING with a threshold of acceptance of $99.9 \%$ (Xaud and Epiphanio, 2014). The maps generated by SPRING were converted to matrix-vector form and exported in a format shape file to ArcGIS for cartographic mapping and quantification of thematic classes using the attribute calculator.

We visited the study area in 2014 and 2015 to take photographs of the area and collect Ground Control Points (GCPs) to support the classification of the satellite images.

The soil map for the basin was edited and quantified using ArcGIS software. This soil map was obtained from the web site of the Instituto Brasileiro de Geografia e Estatística (IBGE); the scale of the map was 1:250,000 (IBGE, 2017).

We classified the soil of the Pantanal subregion of Cáceres into eight classes; they were: Plinthosols (PT); Gleysols (GL); Planosols (PL); Arenosols (AR); Alisols (AL); Ferralsols (FR); Fluvisols (FL); and Leptosols (LP) (Fernandes et al., 2007).

\subsection{Model specification}

All modeling was conducted using RStudio statistical software version 1.0.153 (RStudio, 2015). We used the lme4 package (Bates et al., 2015a) to obtain R (R Core Team, 2015). According to Bates et al. (2015b), the package provides functions that fit and analyze linear mixed, generalized linear, mixed, and nonlinear mixed models.

The analyzed geocoded data consists of polygons, each identified by a pair of coordinates based on: year of data collection (five distinct years); area of the polygon (in hectare); land use type (six classes); and soil type (eight classes). The first inputs are numerical and the latter are categorical. The spatio-temporal data consists of an average of 19,000 polygons per year over five different years.

Linear mixed models (LMMs) are the short-reference to linear mixed-effect models in which both fixed and random-effect terms, along with their variance and covariance components, are considered. These models can be expressed in different but equivalent forms appropriate for representing grouped data, i.e., when data are gathered over time or when data consists of clusters of related statistical units. In our case, these clusters are land use type.

With the goal of modeling LUC over time, our model can be presented in matrix form as follows: 


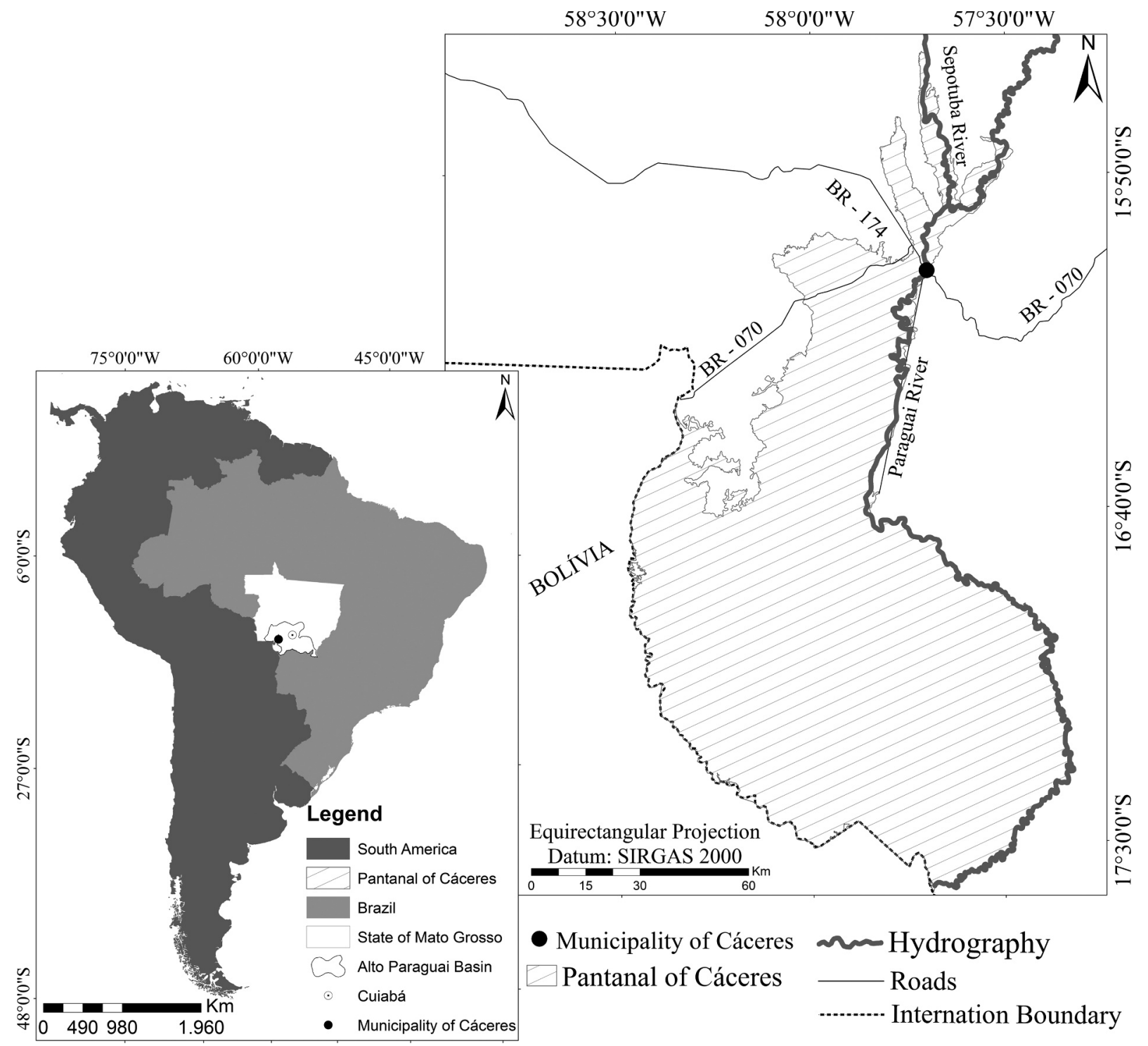

Fig. 1. Map of Pantanal subregion of Cáceres, Mato Grosso State, Brazil.

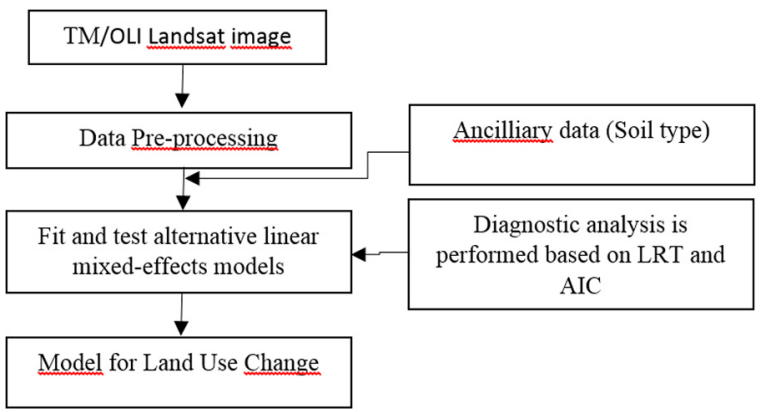

Fig. 2. Methodology flowchart (LRT is the Likelihood-Ratio Test and AIC is the Akaikes Information Criterion).

$$
\begin{aligned}
\mathbf{y}_{i} & =\mathbf{X}_{i} \beta+\mathbf{Z}_{i} \mathbf{b}_{i}+\epsilon_{i}, \\
\mathbf{b}_{i} & \sim \mathbf{N}_{q}(\mathbf{0}, \Psi) \\
\epsilon_{\boldsymbol{i}} & \sim \mathbf{N}_{n_{i}}\left(\mathbf{0}, \sigma^{2} \mathbf{I}_{n_{i}}\right)
\end{aligned}
$$

where $N_{q}$ and $N_{n_{i}}$ are multivariate normal distributions of dimension $q$ and $n_{i}$, respectively, and $\mathbf{y}_{i}$ is the $n_{i} \times 1$ response vector representing area measurements in the $i$ th category of land use type. The $n_{i}$ need not be equal. $\mathbf{X}_{i}$ is the $n_{i} \times p$ model matrix of fixed-effect regressors representing observations in the $i$ th use type category. Examples of regressors, also commonly referred to as explanatory variables, are year or soil type. $\beta$ is the $p \times 1$ vector of the fixed-effect coefficients, which are assumed invariant for all land use types. $\mathbf{Z}_{i}$ is the $n_{i} \times q$ matrix of regressors for the random effects for observations in the ith category of use type. $\mathbf{b}_{i}$ is the $q \times 1$ vector of random effects coefficients for land use type $i, \epsilon_{i}$ is the $n_{i} \times 1$ vector of errors for area measurements in the $i$ th category of use type, $\Psi$ is the $q \times q$ covariance matrix for the random effects, and $\mathbf{I}_{n i}$ is the identity matrix of dimension $n_{i}$.

In our study, we also used a Generalized linear mixed model (GLMM). GLMMs are a class of more flexible linear mixed models that, rather than modeling responses directly, apply a link function $g($.$) . A$ GLMM is an extension of a generalized linear model (GLMs), because it adds random effects to the linear predictor of a GLM and expresses the expected value of the response conditional on the random effects.

To understand LUC data over time, we modeled areas of polygon obtained from images composites over five different years. An exploratory analysis of our spatio-temporal data indicated there were some response variables that were gross outliers. Consequently, we used the logarithm as the link function $g($.$) as a mitigation approach to$ address the presence of outliers. In matrix form, the GLMM is 

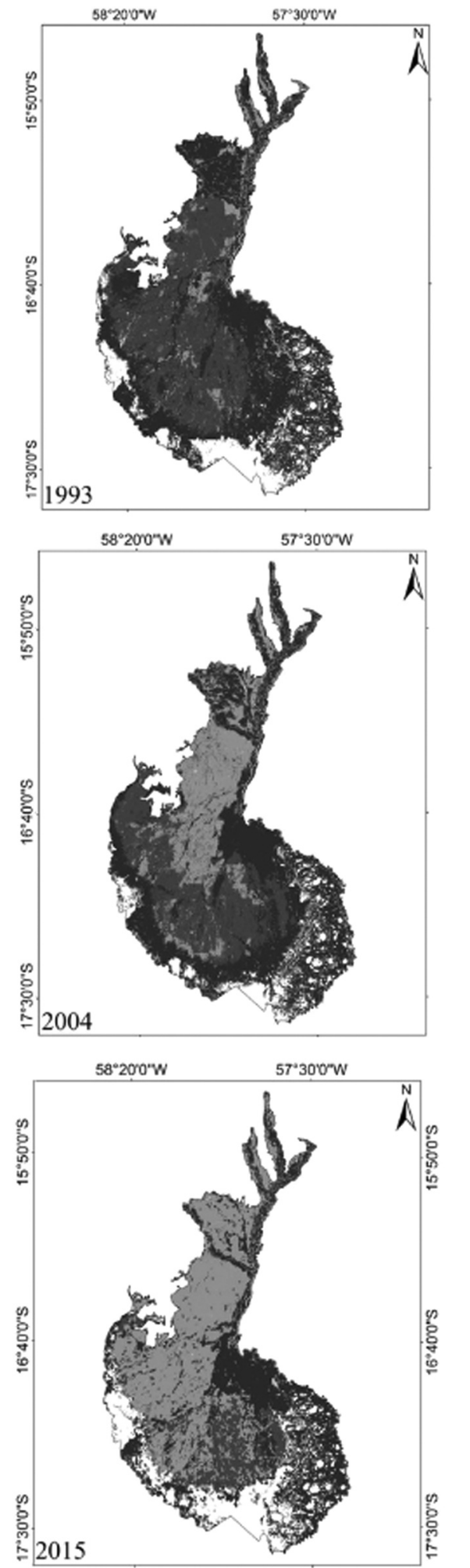
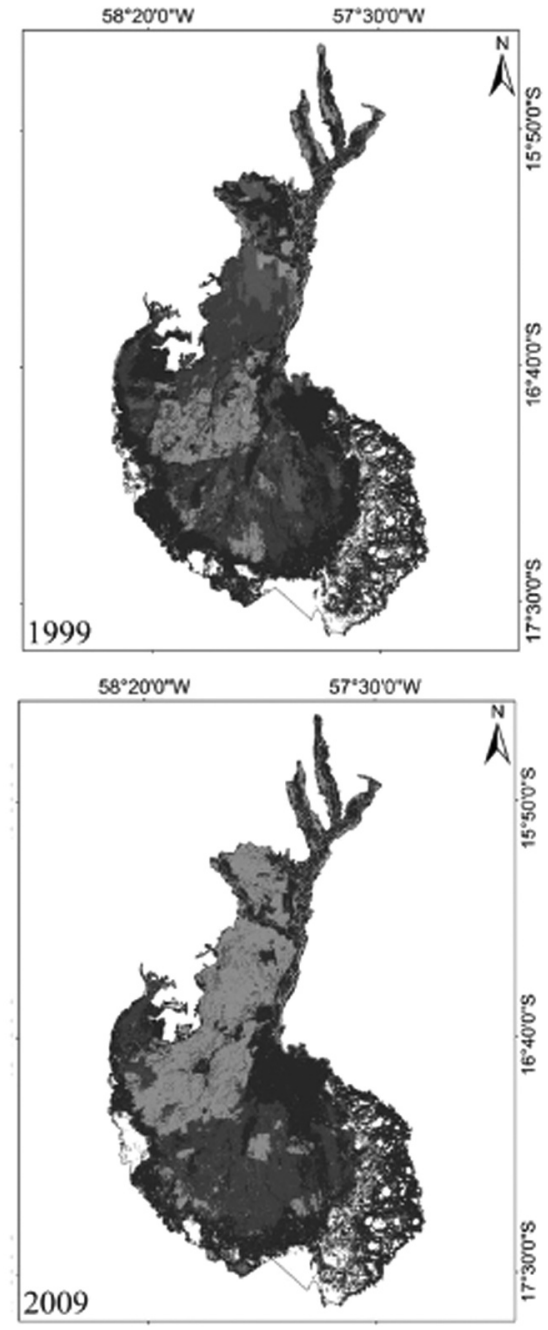

Forest

Pasture

Savanna

Water

Bumed

Others Use

Equirectangular Projection

Datum: SIRGAS 2000

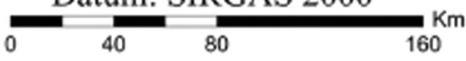

Fig. 3. Distribution of thematic land use classes in the Pantanal subregion of Cáceres in 1993, 1999, 2004, 2009 and 2015.

$\eta_{i}=\mathbf{X}_{i} \beta+\mathbf{Z}_{i} \mathbf{b}_{i}$

$$
\begin{aligned}
g\left(\mu_{\boldsymbol{i}}\right) & =g\left(E\left[\mathbf{y}_{i} \mid \mathbf{b}_{i}\right]\right)=\eta_{\boldsymbol{i}} \\
\mathbf{b}_{i} & \sim \mathbf{N}_{q}(\mathbf{0}, \boldsymbol{\Psi}) \\
\mathbf{b}_{i} & \neq \mathbf{b}_{i^{\prime}} \text { are independent for } \neq \neq i^{\prime}
\end{aligned}
$$

where $\mu_{i}$ is the $n_{i} \times 1$ expectation vector for the response, the area measurements, conditional on the random effects. $\eta_{i}$ is the $n_{i} \times 1$ linear predictor for the elements of the response vector. $g()=.\log ($.$) is the link$ function, transforming the conditional expected response to the linear predictor.

\subsection{Statistical analysis}

Prior to model fitting, we conducted an exploratory data analysis to gain insight into our spatio-temporal data. R statistical software offers many ways to easily summarize and visualize the most important 


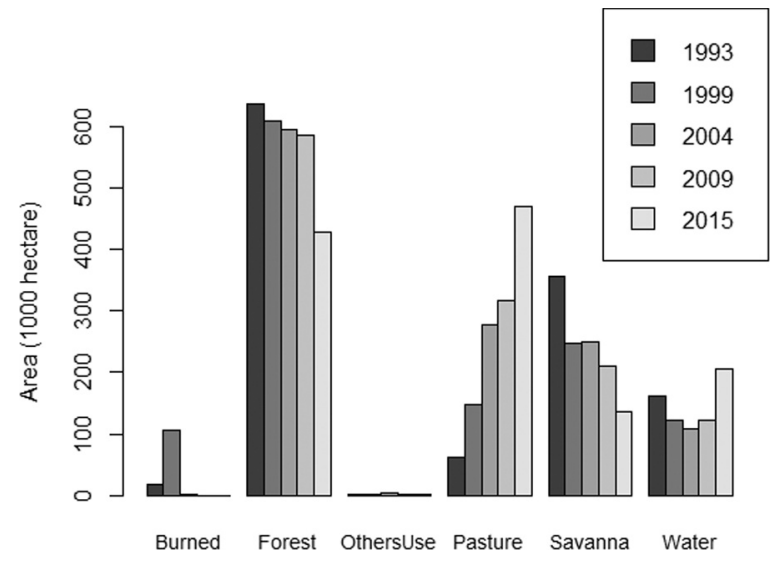

Fig. 4. Distribution of area use type.

Table 1

Summary of AIC values obtained for the linear mixed models. Model 1 (M1) and Model 2 (M2) are Linear Mixed Models (LMMs). Model 3 (M3) and Model (M4) are Generalized Linear Mixed-Models (GLMMs).

\begin{tabular}{ccccc}
\hline Models & M1 & M2 & M3 & M4 \\
\hline AIC & $1,736,930$ & $1,736,851$ & $824,537.8$ & $824,289.7$ \\
\hline
\end{tabular}

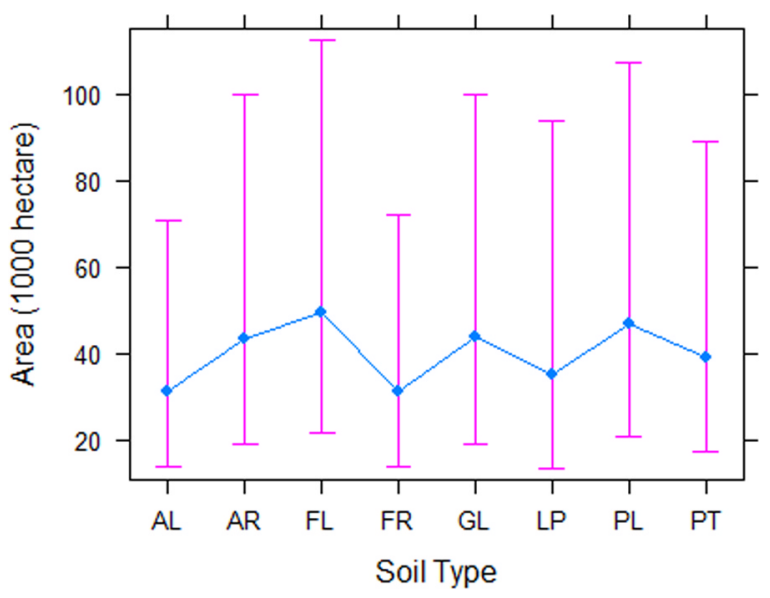

Fig. 5. Estimates and standard deviations for the fixed-effect coefficients $\beta$ in model M4 with respect to the eight soil types, namely: Plinthosols (PT), Gleysols (GL), Planosols (PL), Arenosols (AR), Alisols (AL), Ferralsols (FR), Fluvisols (FL) and Leptosols (LP).

characteristics of a data set. We used the table function to build contingency tables showing the number of each categorical variable, such as soil type or land use type.

We also produced boxplots to display groups of area measurements (i.e., graphically comparing grouped values), which is useful for analyzing data symmetry and determining the presence of outliers. The barplot function, which creates bar plots with vertical or horizontal bars, proved useful for handling large datasets. We used this function to graphically compare the area distribution (over time) with respect to land use type.

The Akaikes Information Criterion (AIC) is frequently used to compare multiple models fit to the same database (Burnham and Anderson, 2002). The criterion supports choosing the model that minimizes the AIC. We chose one that captures the primary underlying characteristics of a dataset. We compared several models with different structures for random effects, e.g., the random intercept or both the random intercept and the slope, while allowing the slope to be correlated or uncorrelated. We also considered different fixed-effects in the analyzed mixed models.

We tested hypotheses on the variances and covariances of the random effects by deleting the random-effects terms from the model and maintaining identical fixed-effects (i.e., nested models). Tests were based on the change in the log of the maximized likelihood, i.e., the ( $\log$ ) likelihood-ratio tests (LRT). In the R environment, the Analysis of variance (ANOVA) function was used as the LRT to compare nested models, providing significance testing of both fixed and random effects. If two models under comparison were not nested, then the AIC was chosen over the LRT.

\section{Results}

\subsection{Exploratory analysis}

In this section, we present and analyze the results obtained using the proposed methods, starting with the thematic map (Fig. 3). After that we present the data graphically.

The classification shown in Fig. 3 provides an overview of the major land use features present in the Pantanal subregion of Cáceres in the state of Mato Grosso, Brazil, from 1993 to 2015. The Pantanal subregion of Cáceres is a sub-region comprising the Floristic Contacts of the Ecotonic type between the Pioneer Formations and Cerrado, the tree Savanna (Cerrado), and the grassy-woody Savanna (field), which represent $75 \%$ of the vegetation cover in the region (Abdon and Silva, 2006).

Over the study period, an expansion of the area of the pasture class is observed. In the Pantanal, the conversion is from forest to pasture, particularly in the upland areas (the ridges), as discussed in Brasil (2010) and WWF (2010).

The graph in Fig. 4 shows the area distribution over the five distinct years of analysis, showing the land use variation over time. In Fig. 4, one observes that the areas per land use type increase or decrease linearly over time. In addition, the slopes and intercepts vary, which suggests a model with random slopes and intercepts (Equations (M1)(M4)).

In particular, Fig. 4 indicates that the area of the Pasture increases, and the area of the Forest and Savanna decrease over time. The Burned areas constitutes a large portion of the study area in 1993 and 1999. This is relevant because the local vegetation is characterized by different behavior in times of drought (Rodrigues et al., 2002), which favors the incidence and spread of fire, in addition to other climatic factors, such as high temperature, low humidity, and wind.

\subsection{Modeling results}

As we did in our exploratory data analysis, we started our modelbased approach with a simple model (M1), which is a particular case of Eq. (1), as follows:

Area $_{i j}=\beta+b_{1 i}+b_{2 i} \times$ Year $_{i j}+\epsilon_{i j}$,

where Area $_{i j}$ represents the area measurement for the $j$ th polygon within the ith category of land use type, $\beta$ is a common fixed intercept, $b_{1 i}$ identifies the random intercepts per land use type, $b_{2 i}$ represents the random slopes per land use type as a function of year, and $\epsilon_{i j}$ is the error of the observation $j$ in use type $i$. To confirm the importance of the random slopes $b_{2 i}$, we performed a likelihood-ratio test (LRT), obtaining a $p$-value 0.01146 .

Next, we attempted to include soil type as a fixed-effect in the model (M2), as follows:

Area $_{i j}=\beta \times$ SoilType $_{i j}+b_{1 i}+b_{2 i} \times$ Year $_{i j}+\epsilon_{i j}$,

where $\beta$ is a vector of fixed-effect coefficients associated with the eight categories of soil type.

Models M1 and M2 are nested; thus, an LRT can be adopted to test for significant differences between the two. Fox and Weisberg (2015) 


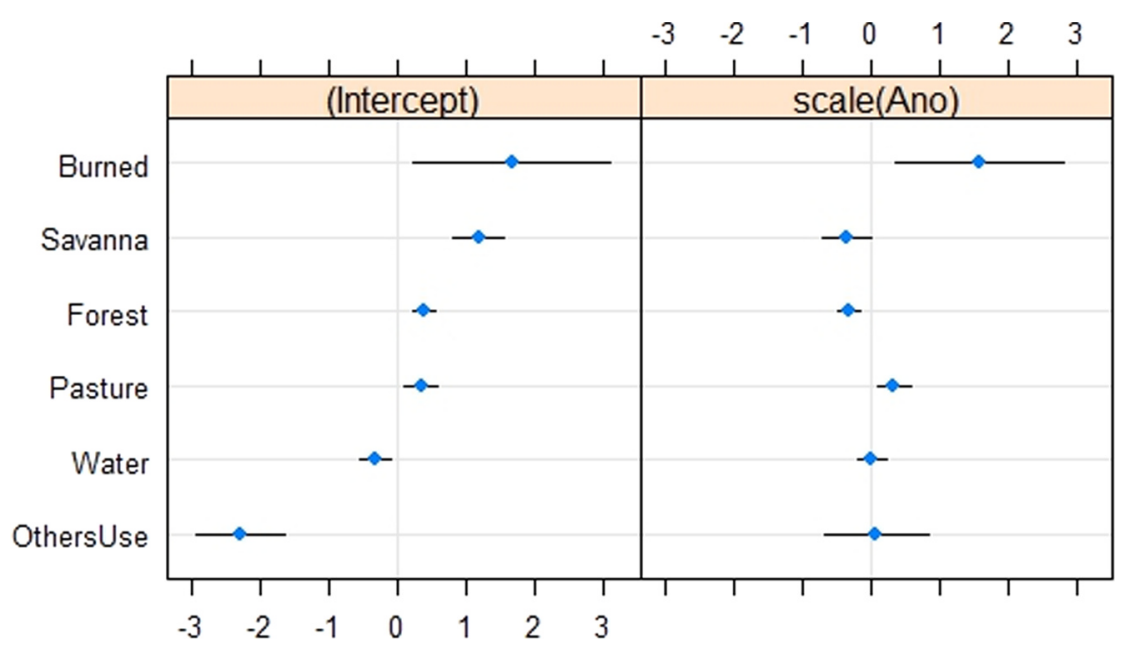

Fig. 6. The 95-percent confidence intervals for the random intercepts $b_{1 i}$ (left-panel) and random slopes $b_{i 2}$ (right-panel) in model (M4).

did not perform an LRT for fixed-effects when the mixed model was fitted by the restricted maximum likelihood (REML), as it is in the lme4 package (lmer function). Therefore, when performing ANOVA, we refitted models with ML instead of REML. The $p$-value obtained from the LRT was 0.9917. This large $p$-value indicates that it is not evidence to adopt model M2, which excludes the explanatory variable "soil type" from the analysis.

Our next model, M3, is defined as a particular case of Eq. (2), with which we tested whether there were advantages of using the generalized linear mixed model.

$$
\begin{aligned}
& \eta_{i j}=\beta+b_{1 i}+b_{2 i} \times \text { Year }_{i j}, \\
& \log \left(\mu_{i j}\right)=\log \left(E\left[\text { Area }_{i j} \mid b_{1 i}, b_{2 i}\right]\right)=\eta_{i j} \\
& {\left[\begin{array}{l}
b_{1 i} \\
b_{2 i}
\end{array}\right] \sim \mathbf{N}_{2}\left(\left[\begin{array}{l}
0 \\
0
\end{array}\right],\left[\begin{array}{ll}
\psi_{11} & \psi_{12} \\
\psi_{21} & \psi_{22}
\end{array}\right]\right)} \\
& b_{k i} \neq b_{k i^{\prime}} \text { are independent for } \neq \neq i^{\prime}
\end{aligned}
$$

where $\mathbf{N}_{2}$ is a Multivariate Normal of dimension two, $\psi_{11}$ represents the variance of the random intercepts, $\psi_{22}$ represents the variance of the random slopes, and $\psi_{12}$ represents the covariance between these two random effects. Moreover, $\mu_{i j}$ is the expected area measurement for the $j$ th polygon in the $i$ th use type, and $\eta_{i j}$ is the corresponding linear predictor. The GLMM was fitted by maximum likelihood (Laplace Approximation), using the glmer function of the lme4 package.

In comparing models $\mathrm{M} 1$ and M3, we observed that the corresponding AIC values dropped from 1,736,930 to 824,537.8 (see Table 1), strongly supporting the use of the log-link in our model. Notably, the standard deviation of the error measurements, $\epsilon_{i j}$, dropped from 1358.82 to 17.2 .

Lastly, we employed a GLMM, in which the soil type is considered to be a fixed-effect. The new model, M4, is an extension of M3 that changes the linear predictor $\eta_{i j}$ as follows:

$\eta_{i j}=\beta \times$ SoilType $_{i j}+b_{1 i}+b_{i 2} \times$ Year $_{i j}$.

Table 1 presents a summary of AIC values obtained for the four linear mixed models under consideration. Model M4 is preferable to model M3 due to its lower AIC value. Based on the LRT, in which M3 and M4 are equivalent under the null hypothesis, we obtained a $p$-value $\approx 0$, showing the advantages of M4.

We present a summary of the results obtained using M4. Fig. 5 gives the estimated fixed-effect coefficients and corresponding standard deviations. These results reveal how the type of soil explains the area measurements per land use type.

We conclude that there is no statistically significant difference between Alisols (AL), Ferralsols (FR) and Leptosols (LP) soil types.
Fluvisols has the largest area, (FL), followed by Planosols (PL) and Gleysols (GL).

Hydromorphic soils are common in the Pantanal, being "subject to alternating periods of natural flooding and drying, leading to formation and differentiated characteristics" (Coringa et al., 2012). In particular, the Planosols (PL) and Gleysols (GL) soils are saturated with sodium. In addition, pasture areas are prone to flooding, which likely explain the land cover of areas with this soil (Santos et al., 1997).

Based on the covariance matrix of random effects, we conclude that: $\hat{\psi}_{11}=490.6 ; \hat{\psi}_{22}=142.5$; We also observe that the correlation between the random intercepts and random slopes is 0.39. Furthermore, the standard deviation of the error measurements, $\epsilon_{i j}$, is 17.27.

The left-panel of Fig. 6 shows 95-percent confidence intervals (CI) for the random intercepts, represented by $b_{i 1}$ in Equation (M4).

Because our primary goal is to understand the land use changes in the Pantanal over the 22-years of study, understanding the random slopes $b_{2 i}$ appearing in Equation (M4) and listed in the right-panel of Fig. 6 is important. We conclude that the Savanna and the Forest classes show a statistically significant negative slope over time, while the Pasture class shows a positive slope.

In particular, in the case of the Pasture class, the value of the random slope is 0.043 , which indicates an increase of about $21.5 \%$ in hectare over the next 5 years; The point estimate of the slope for the Forest was -0.04 , which indicates a decrease of about $20.5 \%$ in hectare in next 5 years, assuming all other factors are fixed.

\section{Conclusions}

A formal framework for LUC analysis supported by mixed-effects modeling was proposed, evaluated, and used to determine LUC in the Brazilian Pantanal subregion of Cáceres. The framework was based on spatio-temporal data obtained using multi-year satellite imagery. Data collected in five year were processed and analyzed using ArcGIS software. We then compared four statistical models incorporating both fixed and random-effects in the R environment.

Two LMMs and two GLMMs were compared using categorical and numerical data. M1 considered random intercepts per land use type and the random slopes per land use type as a function of year. M2, as an extension of M1, considered the soil type as a fixed-effect. The GLMM models M3 and M4 were fitted to maximum likelihood (Laplace Approximation), using the glmer function in the lme4 package. Finally, in M4, an extension of M3, the soil type was considered to be a fixedeffect. The diagnostic analysis using LRT and AIC indicated that M4 performed best among the tested models.

The final model M4 revealed that, over the period 22-year study period, there was a statistically significant positive slope for the Pasture 
class and negative slopes for the Savanna and Forest classes. Incorporating the soil type into M4 as a fixed-effect helped improve the characterization of the LUC interactions.

This study illustrates that combining remote sensing, GIS, and GLMM offers a formal framework useful for the spatio-temporal analysis of LUC that is otherwise difficult using conventional techniques. The statistical analysis has proven to be a powerful tool for analyzing LUC, as it allows one to rank relative factors and to formally test alternative hypotheses.

Another direction for future study is the extension of the method to multilevel models for characterizing the LUC on a season by season basis. Examining other measures, such as rainfall, relief, and vegetation indices and using modeling approaches similar to those discussed here may help in an analysis of LUC in wetland areas.

\section{Acknowledgements}

This research was financed by the Mato Grosso State Research Foundation, Brazil (FAPEMAT).

\section{References}

Abdon, M.M., Silva, J.S.V., 2006. Fisionomias da vegetação nas sub-regiões do Pantanal Brasileiro. São José dos Campos: INPE; Campinas: Embrapa Informática Agropecuária.

Adamoli, J., 2005. Zoneamento ecológico do Pantanal baseado no regime de inundações. In: Encontro Sobre Sensoriamento Remoto Aplicado a Estudos no Pantanal, 1, 1995, Corumbá. Anais. São José dos Campos: Inpe. 15-17.

Alho, C.J.R., Silva, J.S.V., 2012. Effects of severe floods and droughts on wildlife of the Pantanal wetland (Brazil). A Rev. Anim. 2 (4), 591-610.

ANA - Agência Nacional de Águas, 2005. Strategic action program for the integrated management of the Pantanal and the upper Paraguay river basin, Brasília, DF: ANA/ GEF/PNUMA/OEA, 315 p.

Bates, D., Maechler, M., Bolker, B.M., Walker, S., 2015a. lme4: linear mixed-effects models using eigen and S4. R Package Version 1, 1-10(URL 〈http://CRAN.R-project. org $/$ package $=\operatorname{lme} 4>$ ).

Bates, D., Maechler, M., Bolker, B.M., Walker, S., 2015b. Fitting linear mixed-effects models using lme4. J. Stat. Softw. 67 (1), 1-48. https://doi.org/10.18637/jss.v067. i01.

Bove, C.P., Gil, A.S.B., Moreira, C.B., Anjos, R.F.B., 2004. Hidrófitas fanerogâmicas de ecossistemas aquáticos temporários da planície costeira do Estado do Rio de Janeiro. Bras. Acta Bot. Bras. 17, 119-135.

Brasil, 2009. Biomas: Pantanal. 〈http://www.mma.gov.br/biomas/pantanal〉. (Accessed 15 July 2017).

Brasil, 2010. Ministério do Meio Ambiente. Monitoramento do desmatamento nos Biomas Brasileiros por satélite. Acordo de Cooperação Técnica MMA/IBAMA: Monitoramento Bioma Pantanal 2002 a 2008. Brasília.

Burnham, K., Anderson, D., 2002. Model Selection and Multimodel Inference: A Practical Information-Theoretic Approach, 2nd edn. Springer-Verlag, New York.

Camara, G., Souza, R.C.M., Freitas, U.M., Garrido, J., Ii, F.M., 1996. SPRING: integrating remote sensing and GIS by object-oriented data modelling. Comput. Graph. 20 (1), 395-403.

Clements, N., Sarkar, S.K., Zhao, Z., Kim, D., 2014. Applying multiple testing procedures to detect change in east African vegetation. Ann. Appl. Stat. 8 (1), 286-308.

Coringa, E.A.O., Couto, E.G., Perez, X.L.O., Torrado, P.V., 2012. Attributes of the hydromorphic soils in the Pantanal of North Matogrosso. Acta Amaz. 42 (1), 19-28.

Csaplovics, E., 1998. High Resolution space imagery for regional environmental monitoring - status quo and future trends. Int. Arch. Photo. Rem. Sens. 32 (7), 211-216.

R Core Team, 2015. R: A language and environment for statistical computing. R Foundation for Statistical Computing, Vienna, Austria. 〈http://www.R-project.org/〉.
Dallacort, R., Neves, S.M.A.S., Nunes, M.C.M.N., 2014. Variabilidade da temperatura e das chuvas de Cáceres/PantanalMato-Grossense - Brasil. Geogr. (Londrina) 23 (1), 21-33.

Esri, 2007. Arcgis Desktop: Release 9.2. Redlands, Ca: Environmental Systems Research Institute.

Fernandes, F.A., Fernandes, A.H.B.M., Soares, M.T.S, Pellegrin, L.A., Lima, I.B.T., 2007. Atualização do mapa de solos da planície pantaneira para o Sistema Brasileiro de Classificação de Solos. Corumbá: Embrapa Pantanal, 6 p. (Embrapa Pantanal, Comunicado Técnico, 61). 〈http://www.cpap.embrapa.br/publicacoes/〉. (Accessed 12 August 2017).

Foody, G.M., 2002. Status of land cover classification accuracy assessment. Rem. Sens. Environ. 80, 185-201.

Fox, J., Weisberg, S., 2015. Mixed-effects models in R. An Appendix to AnR Companion to Applied Regression, Second Edition.

IBGE, Instituto Brasileiro de Geografia e Estatística, 2004. Mapas de biomas e de vegetaççãao. 〈http://www.ibge.gov.br/home/presidêencia/noticias/ 21052004biomashtml.sht〉. (Accessed 2 August 2017).

IBGE, Instituto Brasileiro de Geografia e Estatística, 2013. Manual técnico de uso da terra, 3nd ed. Rio de Janeiro: IBGE.

IBGE, Instituto Brasileiro de Geografia e Estatística, 2017. Pedo-logia. 〈https://www. ibge.gov.br/geociencias-novoportal/informacoes-ambientais/pedologia/10871pedologia.html? \&t = downloads $>$. (Accessed 2 July 2018).

Neves, S.M.A.S., Cruz, C.B.M., Neves, R.J., 2008. Operacionalizaçcãão de propostas de Zoneamento turíístico do Pantanal de Cááceres/MT, com suporte nas geotecnologias. Ciêência Geográáfica 18, 76-86.

Pott, V.J., Pott, A., Lima, L.C.P., Moreira, S.N., Oliveira, A.K.M., 2011. Aquatic macrophyte diversity of the Pantanal wetland and upper basin. Braz. J. Biol. 71 (1) 255-263.

Pramudya, Y., Dewi, W.S., Sukoco, T.A., Rozaki, Z., et al., 2016. Remote sensing for estimating agricultural land use change as the impact of climate change. Land Surf. Cryosphere Remote Sens. III 9877.

Rawat, J.S., Kumar, M., 2015. Monitoring land use/cover change using remote sensing and GIS techniques: a case study of Hawalbagh block, district Almora, Uttarakhand, India. Egypt. J. Remote Sens. Space Sci. 1 (18), 77-84.

Rodrigues, C.A.G., Crispim, S.M.A., Comastri Filho, J.S., 2002. Queima controlada no Pantanal/Corumbá: embrapa Pantanal; $22 \mathrm{~cm}$ - Embrapa Pantanal. Documentos $35,22$.

Rosa, R., 2003. Introdução ao sensoriamento remoto, 5nd ed. Ed. da Universidade Federal de Uberlândia.

RStudio Team, 2015. RStudio: Integrated development for R, RStudio, Inc., Boston, MA. URL 〈http://www.rstudio.com/〉.

Santos, R.D., Carvalho Filho, A., Naime, U.J., Oliveira, H., Motta, P.E.F., Baruqui, A.M., Barreto, W.O., Melo, M.E.C.C.M., Paula, J.L., Santos, E.M.R., Duarte, M.N., 1997. Pedologia. In: Plano de conservação da Bacia do Alto Paraguai - PCBAP: diagnóstico dos meios físico e biótico - meio físico.Brasília, DF: PNMA, v.2, t.1, p.127-307.

Silva, J.S.V., Abdon, M.M., 1998. Delimitaççãão do Pantanal brasileiro e suas subregiõões. Pesq. Agropec. Bras. 33, 1703-1711.

Silva, C.J., Girard, P., 2004. New challenges in the management of the Brazilian Pantanal and catchment area. J. Ecol. Manag. 12, 553-561.

USGS. United States Geological Survey, 2017. Landsat-8. 〈http://landsat.usgs.gov〉. (Accessed 5 August 2017).

Veldkamp, A., Lambin, E.F., 2001. Predicting land-use change. Agric. Ecosyst. Environ. 85 (1-3), 1-6.

Wantzen, K.M., Cunha, C.N., Junk, W.J., Girard, P., Rossetto, O.C., Penha, J.M., Couto, E.G., Becker, M., Priante, G., Tomas, W.M., Santos, S.A., Marta, J., Domingos, I., Sonoda, F., Curvo, M., Callil, C.T., 2008. Towards a sustainable management concept for ecosystem services of the Pantanal wetland. Ecohydrol. Hydrobiol. 8, 115-138.

Weng, Q., 2002. Land use change analysis in the Zhujiang Delta of China using satellite remote sensing, GIS and stochastic modelling. J. Environ. Manag. 64 (3), 273-284.

World Wildlife Fund - (WWF), 2010. Monitoramento das alteraçções da cobertura vegetal e uso do solo na Bacia do Alto Paraguai. 〈http://www.wwf.org.br/in-formacoes〉. (Accessed 9 August 2017).

Xaud, M.R., Epiphanio, J.C.N., 2014. Dinâmica do uso e cobertura da terra no sudeste de Roraima utilizando técnicas de detecção de mudanças. Acta Amaz 44 (2), 107-120.

Zhu, A.X., 1997. Measuring uncertainty in class assignment for natural resource maps under fuzzy logic. Photogramm. Eng. Remote Sens. 63 (10), 1195-1202. 